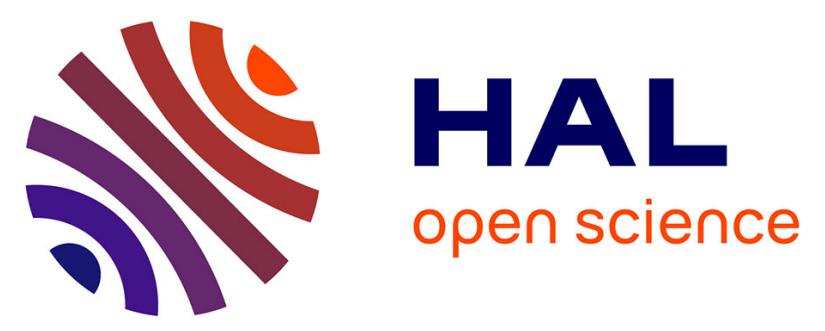

\title{
LIDAR observations of lower stratospheric aerosols over South Africa linked to large scale transport across the southern subtropical barrier
}

Hassan Bencherif, Thierry Portafaix, Jean-Luc Baray, Béatrice Morel, Serge Baldy, Jean Leveau, Alain Hauchecorne, Philippe Keckhut, Ashokabose Moorgawa, Max M. Michaelis, et al.

\section{To cite this version:}

Hassan Bencherif, Thierry Portafaix, Jean-Luc Baray, Béatrice Morel, Serge Baldy, et al.. LIDAR observations of lower stratospheric aerosols over South Africa linked to large scale transport across the southern subtropical barrier. Journal of Atmospheric and Solar-Terrestrial Physics, 2003, 65 (6), pp.707 - 715. 10.1016/S1364-6826(03)00006-3 . hal-01387242

\section{HAL Id: hal-01387242 \\ https://hal.univ-reunion.fr/hal-01387242}

Submitted on 25 Oct 2016

HAL is a multi-disciplinary open access archive for the deposit and dissemination of scientific research documents, whether they are published or not. The documents may come from teaching and research institutions in France or abroad, or from public or private research centers.
L'archive ouverte pluridisciplinaire HAL, est destinée au dépôt et à la diffusion de documents scientifiques de niveau recherche, publiés ou non, émanant des établissements d'enseignement et de recherche français ou étrangers, des laboratoires publics ou privés. 


\title{
LIDAR observations of lower stratospheric aerosols over South Africa linked to large scale transport across the southern subtropical barrier
}

\author{
H. Bencherif a,*, T. Portafaix ${ }^{\mathrm{a}}$, J.L. Baray ${ }^{\mathrm{a}}$, B. Morela ${ }^{\mathrm{a}}$, S. Baldy, J. Leveau ${ }^{\mathrm{a}}$, \\ A. Hauchecorne ${ }^{\mathrm{b}}$, P. Keckhut ${ }^{\mathrm{b}}$, A. Moorgawa ${ }^{\mathrm{c}}$, M.M. Michaelis ${ }^{\mathrm{c}}$, R. Diab ${ }^{\mathrm{d}}$ \\ ${ }^{a}$ Laboratoire de Physique de l'Atmosphère, Université de la Réunion, UMR-CNRS8105, B.P. 7151, 97715, \\ Saint-Denis cedex 9, France \\ ${ }^{\mathrm{b}}$ Service d'Aéronomie du CNRS, Paris, France \\ ${ }^{\mathrm{c}}$ School of Pure and Applied Physics, University of Natal, Durban 4041, South Africa \\ ${ }^{\mathrm{d}}$ School of Life and Environmental Sciences, University of Natal, Durban 4041, South Africa
}

\begin{abstract}
The study of the variability of stratospheric aerosols and the transfer between the different atmospheric regions improves our understanding of dynamical processes involved in isentropic exchanges that take place episodically in the lower stratosphere through the subtropical barrier. One useful approach consists in combining in situ ground-based and global measurements with numerical analyses. The present paper reports on a case study of a horizontal transfer evidenced first by Rayleigh-Mie LIDAR observations over Durban $\left(29.9^{\circ} \mathrm{S}, 31.0^{\circ} \mathrm{E}\right.$, South Africa). Additional data from MeteoSat and SAGE-2 experiments, and from ECMWF meteorological analysis have been used in this study. Contour advection maps of potential vorticity from the MIMOSA model derived from ECMWF fields, were also used.

By the end of April, 1999, LIDAR observations showed that aerosol extinction, in the lower stratosphere, has increased significantly and abnormally in comparison with other LIDAR and SAGE-2 observations recorded for the period from April 20 to June 14,1999 . The dynamical context of this case study seems to exclude the possibility of a local influence of the subtropical jet stream or tropical convection, which could inject air masses enriched with tropospheric aerosols into the stratosphere. On the contrary, a high-resolution model based on PV advection calculations and ECMWF meteorological analyses shows that air masses are isentropically advected from the equatorial zone close to Brazil. They cross the southern barrier of the tropical reservoir due to laminae stretching and reach the southern subcontinent of Africa 5-6 days later.
\end{abstract}

Keywords: LIDAR; Aerosols; Isentropic transport; Stratosphere; Subtropical barrier; PV-contour advection

\section{Introduction}

Aerosols have been shown to have a significant influence on radiative forcing and hence temperature (Robock

\footnotetext{
* Corresponding author.

E-mail address: hassan.bencherif@univ-reunion.fr (H. Bencherif).
}

and Mao, 1992; Labitzki and McCormick, 1992; Kinninson et al., 1994). Furthermore, a survey of aerosols from Mount Pinatubo indicated that aerosol loading has important chemical effects by enhancing heterogeneous reactions (Brasseur and Granier, 1992) and can modify ozone concentrations (Solomon et al., 1996; Roumeau et al., 2000). Knowledge of mass exchange between different parts of the atmosphere is essential in understanding the transport and vertical and spatial distribution of aerosols. Eddy transport barriers 
separate the tropical stratospheric reservoir from the mid-latitude stratosphere (Holton et al., 1995; Haynes and Shuckburgh, 2000). Steep aerosol and trace gas gradients clearly characterize the edges of that reservoir (Grant et al., 1996). Sporadic disruptions of those barriers occur due to planetary wave breaking and the generation of eddies that enhance transport out of the tropics (Waugh, 1993, 1996; Chen et al., 1994; Horinouchi et al., 2000). Since tropospheric air enters the stratosphere mostly through the tropical tropopause, exchanges between the tropics and mid-latitudes have a large influence on the distribution of many long-lived stratospheric constituents.

The transport of aerosols from the tropics to mid-latitudes is well documented in a number of publications. Randel et al. (1993) using global maps obtained from satellite-borne instruments showed that aerosols can be transported through eddy mixing. Waugh and Plumb (1994) using meteorological data sets showed that aerosols can also be transported through isentropic advection. However, most dynamical studies and co-ordinated campaigns focus on the northern hemisphere or on the southern polar region. In the southern hemisphere, dynamical processes are not similar to those studied or observed in the northern hemisphere. Besides, the height-latitude structure of dynamical fields and of disruption mechanisms controlling the release of material between the tropics and mid-latitudes, is still under study. One of the useful approaches consists in combining in situ ground-based and global measurements and modeling.

We report here a case study of an observed tropical/extratropical aerosol loading event detected by LIDAR in the lower southern stratosphere. Analyses take advantage of the high vertical resolution of LIDAR profiles. Developments of large-scale "tongues" through the surf zone are simultaneously surveyed by the MIMOSA high resolution contour advection model based on ECMWF data sets and by water vapor infrared MeteoSat images.

\section{LIDAR instrumentation, aerosol observations and comparisons with SAGE 2}

\subsection{South African LIDAR system}

The present study has been undertaken using LIDAR observations obtained at Durban $\left(30.7^{\circ} \mathrm{S}, 31.0^{\circ} \mathrm{E}\right)$, South Africa. The system was implemented on the campus of the University of Natal within the framework of a bi-lateral Franco-South African cooperation (Service d'Aéronomie of CNRS, Laboratoire de Physique de l'Atmosphère of Reunion Island University and University of Natal).

The LIDAR system operating at Durban is of the RayleighMie type. It uses a Nd:YAG pulsed laser with a repetition rate of $10 \mathrm{~Hz}$ and transmits in the green at $532 \mathrm{~nm}$. The receiver consists of two separate telescopic systems and two photomultiplier detectors. LIDAR observations are thus made through two separate — but instrumentally identical- channels. One channel is allocated to probe the troposphere. It uses the return signal collected by the smaller telescope whose total receiving surface is about $0.03 \mathrm{~m}^{2}$. The other channel has a total receiving surface of about $0.31 \mathrm{~m}^{2}$, and its observation field is directed to receive photons backscattered from stratospheric layers.

Assuming that the observed atmospheric layers behave as a perfect gas in hydrostatic equilibrium, aerosol and temperature profiles can be derived from the return signal backscattered by successive atmospheric layers in the local troposphere and stratosphere (Hauchecorne and Chanin, 1980; Chazette et al., 1995). More information about the instrumental details and temperature profile retrieval method and validation are given by Bencherif et al. (2000). The aerosol profiles are derived from the LIDAR equation using the Klett procedure (Klett, 1981, 1985) that gives a convergent solution to the total volumetric backscatter coefficient $\beta(z)=\beta_{\text {aerosol }}(z)+\beta_{\text {molecular }}(z)$. The backscatter ratio $R(z)$ (total to molecular volume backscatter coefficient ratio) is then calculated from

$R(z)=\frac{\beta_{\text {aerosol }}(z)+\beta_{\text {molecular }}(z)}{\beta_{\text {molecular }}(z)}=1+\frac{\beta_{\text {aerosol }}(z)}{\beta_{\text {molecular }}(z)} \geqslant 1$.

Values of $R(z)$ depend on the choice of Rayleigh parameters (molecular contribution) which should be as realistic as possible. For the present study, molecular parameters are computed on the basis of ECMWF daily fields. It allows a better determination of the molecular density profile than that of a climatological model (Keckhut et al., 1993).

Moreover, the determination of the total volumetric backscatter coefficient from the LIDAR equation requires quantitative knowledge of a relationship between the aerosol extinction coefficient $\alpha_{\text {aerosol }}(z)$ and the aerosol backscatter coefficient $\beta_{\text {aerosol }}(z)$, usually the ratio $\alpha_{\text {aerosol }}(z) / \beta_{\text {aerosol }}(z)$ (Klett, 1981). That ratio depends strongly on the size, shape and refractive index of the aerosols. Accounting for micro-physical properties of stratospheric aerosols, Wang et al. (1989) estimated the value of this ratio for particles to be $30 \mathrm{sr}$ around $15 \mathrm{~km}$, increasing with altitude up to $50 \mathrm{sr}$ at $28 \mathrm{~km}$. Here, the ratio of extinction to back-scattering coefficient of aerosols is considered to be $50 \mathrm{sr}$ throughout the whole stratospheric altitude range. The Klett procedure also requires a boundary condition, i.e., the knowledge of $\beta_{\text {aerosol }}$ at a reference altitude $z_{\text {ref }}$, chosen above the aerosol layer: at and above this reference altitude, the particle content is negligible and scattering is only due to the molecular atmosphere, assuming that $R(z)=1.0$. Typically, we choose $z_{\text {ref }} \approx 40 \mathrm{~km}$.

Uncertainties in the determination of the total volumetric backscatter coefficient $\beta$ and in the aerosol extinction coefficient $\alpha_{\text {aerosol }}$ and in the backscatter ratio $R$ are due to three main causes: (1) statistical fluctuations of the measured signal associated with random detection processes, $(2)$ the presence of particles at and above the chosen reference altitude and (3) the subsequent uncertainty on the value of $R\left(z_{\mathrm{ref}}\right)$, and the value of the ratio of extinction to back scattering 
coefficient of aerosols and its altitude dependence. The resulting total uncertainty is less than $7 \%$, with the signal being significant up to $40 \mathrm{~km}$ (Chazette et al., 1995).

The algorithm used here is similar to the one used to retrieve aerosol LIDAR optical properties from the NDSC primary stations of the Observatoire de Haute-Provence in Southern France (Chazette et al., 1995) and Dumont d'Urville in Antarctica (David et al., 1998). It has thus been tested within the framework of the NDSC comparison of the processing algorithms for stratospheric aerosols (Steinbrecht et al., 1996).

\subsection{Data}

The LIDAR data set used in this study consists of daily records of back scattered photons obtained over Durban during the period from April 21 to June 14, 1999 (22 profiles). Daily LIDAR measurements are time-integrated over about $3.5 \mathrm{~h}$ on average.

In order to validate aerosol extinction profiles derived from LIDAR observations, we use the 5.99 version SAGE-2 (Stratospheric Aerosol and Gas Experiment) measurements. Indeed, the long life (since 1984) and the calibration-independent nature of the SAGE-2 instrument (McCormick, 1987; Thomason et al., 1997) make it well suited for observations of the long-term variability of aerosols and for comparison with other instruments such as LIDARs. For the present work, SAGE-2 data are derived from the 525-nm wavelength channel and are selected depending on:

- the geographical position, i.e., a SAGE-2 profile is selected if its latitude and longitude correspond to the LIDAR position $\pm 6^{\circ}$ of latitude and $\pm 10^{\circ}$ of longitude,

- the time acquisition, i.e., a SAGE-2 profile is selected if it was recorded on the same day as one of the 22 LIDAR profiles $\pm 12 \mathrm{~h}$.

Taking into account the duration of the study, the LIDAR dependency on meteorological conditions and the SAGE-2 operating mode (Chu et al., 1989) which is very different in comparison with the LIDAR's, we expect a very small number of coincidences on the basis of the selection criteria mentioned above. Only one coincident SAGE-2 extinction profile has thus been selected. It was recorded on June 8 , 1999 , sunrise, at $24.8^{\circ} \mathrm{S}$ and $38.4^{\circ} \mathrm{E}$. The corresponding LIDAR profile was recorded on the same day, at Durban, and was time integrated from 16:30 to 19:55 UTC.

In the local stratosphere, the coincident SAGE-2 and LIDAR aerosol extinction profiles, superposed on Fig. 1, show closely similar vertical distribution. Despite the fact that both profiles' error bars overlap in the whole studied altitude range, the observed discrepancy in the $17-20 \mathrm{~km}$ layer is mainly due to the operating modes: SAGE- 2 measurements are obtained by looking through a horizontal path of a few hundred kilometres (solar occultation) and

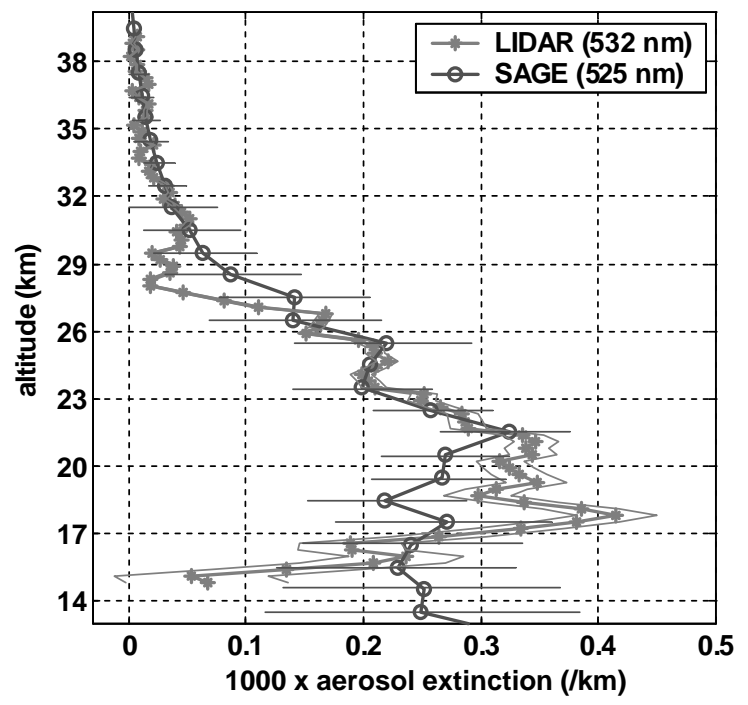

Fig. 1. LIDAR and SAGE-2 aerosol extinction profiles recorded quasi-simultaneously, on June 8, 1999 (see legend). The horizontal lines represent the SAGE-2 error bars. The LIDAR profile is framed by the aerosol extinction profiles at $\pm \sigma$ the total uncertainty.

thus correspond to a horizontally averaged atmosphere, while LIDAR measurements are obtained vertically and are time-integrated over a few hours. It is important to note that other effects can contribute to the mentioned discrepancy: the difference in wavelength between SAGE- 2 and LIDAR, the validity of hypotheses used for the inversion of the LIDAR equation such as the height independence of the aerosol extinction to back-scattering ratio, the spatial inhomogeneity of aerosol distribution and the instrument geometry.

Knowing that all LIDAR profiles used in the present work have been retrieved using the same inversion method, this comparison, even though it is made with one coincidence, shows that the quality of aerosol profiles obtained by LIDAR over Durban is consistent. These observations can be used consequently for climatological studies as well as for the purpose of a case study, within the framework of co-ordinated campaigns or for validation and inter-comparisons.

\section{Results}

From the LIDAR data set described above, an averaged aerosol extinction profile has been derived (see the solid thick line showed in Fig. 2). As expected, note that extinction values of the stratospheric background aerosols decrease rapidly with increasing altitude up to the $28-30 \mathrm{~km}$ altitude range. Beyond that layer, which can be called the local stratospheric aerosol top layer, the observed atmosphere can be considered as typically molecular, i.e., free of aerosols. 


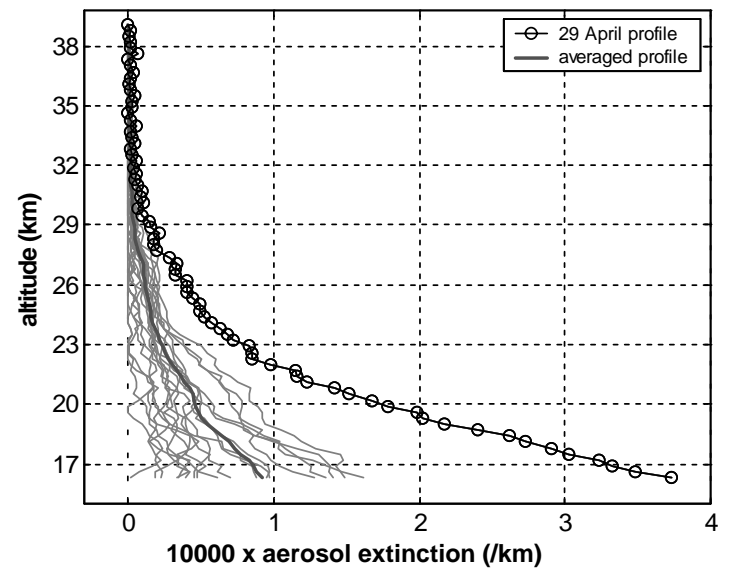

Fig. 2. Aerosol extinction profiles recorded by LIDAR over Durban from April 20 to June 14, 1999. The corresponding averaged profile is shown by the solid thick line (see legend).

Moreover taking into account the extinction mean values the daily LIDAR profiles distribution, illustrated by superposition of all LIDAR profiles in Fig. 2, highlights a high variability of the observed stratospheric aerosols. This variability can be associated to the fact that, during the studied period, the transition of the stratospheric zonal-mean winds to the westerly regime was occurring, as shown by Bencherif et al. (2000).

However, if one considers the 29th of April profile for stratospheric heights under $27 \mathrm{~km}$, the observed extinction values are significantly higher than those of the mean profile and higher too than all other values from all LIDAR profiles. The aerosol increase observed on April 29 is therefore unusual and suggests that, by the end of April, 1999, aerosol extinction has increased significantly and abnormally in the lower stratosphere, as a result of an aerosol loading through a transport process.

For a discussion of the origin of the stratospheric aerosol loading observed over Durban two possible origins are investigated; the first is related to vertical transport from the troposphere to the stratosphere, the second to horizontal transfer between the tropics and extra-tropics.

\section{Discussion on the origin of the aerosol loading over South Africa}

\subsection{Dynamical characteristics of the stratospheric air mass over South Africa on April 29}

Potential vorticity (PV) contours for the $400 \mathrm{~K}$ potential temperature level, in the lower stratosphere, have been computed from ECMWF data for the whole studied period. ECMWF data used in this study are re-analysed data, with a horizontal resolution of $1^{\circ}$ by $1^{\circ}, 15$ vertical levels between 1000 and $10 \mathrm{hPa}$, and with 4 fields per day. These data have already been used for tropospheric-stratospheric dynamical studies in the tropical southern hemisphere (Baray et al., 2000).

Fig. 3 shows the latitude vs. longitude PV field for the $400 \mathrm{~K}$ isentropic surface, averaged for the period April 18 to May 10, 1999, that corresponds to the aerosol loading event date \pm 10 days. The mean value of PV over the LIDAR site of Durban lies between 7 and 8 PVU. The PV field of April 29 is presented in Fig. $3 \mathrm{~b}$ and shows a zone of low-PV $(2 \leqslant \mathrm{PV} \leqslant 5 \mathrm{PVU})$ lying between $25^{\circ} \mathrm{S}$ and $35^{\circ} \mathrm{S}$ and $20^{\circ} \mathrm{E}$ and $45^{\circ} \mathrm{E}$. With the exception of the equatorial zone, the lowest $\mathrm{PV}$ values (PV $\leqslant 3 \mathrm{PVU}$ ) appear around the $27^{\circ} \mathrm{S}$ and $39^{\circ} \mathrm{E}$ position. This low-PV air mass either has a local upper-tropospheric origin or has originated from long range isentropic quasi-horizontal transport.

\subsection{A local tropospheric origin?}

The dynamic mechanisms which can induce a transfer from the upper troposphere to the lower stratosphere are tropical convection and jet-streams (polar and subtropical). An examination of the Meteosat image for April 29 (Fig. 4) shows that there was virtually no cloud cover over Durban on April 29, thus precluding the possibility of locally strong convective activity capable of injecting an air mass enriched in tropospheric aerosols into the lower stratosphere.

Tropospheric jets/frontal systems are a very perturbed zone and can induce areas of convergence and subsidence, in association with horizontal and vertical ageostrophic circulations. They can result either in strong subsiding motions in tropopause folds, or in strong ascending motion, generally on the anticyclonic side near the entrance zone of the jet stream (Shapiro and Kennedy, 1981; Holton et al., 1995). In our case study, the upper level front associated with the subtropical jet stream is clearly visible on the Meteosat image (Fig. 4) and is localised in the middle of the Atlantic Ocean, far from the south-western coast of Africa. Within the upper troposphere, winds over Durban are weak, and no $\mathrm{PV}$ signature is visible (ECMWF data, not shown). Hence we can conclude that the lower stratosphere over Durban has not been influenced by a local tropospheric source, either by convective activity or by the jet stream.

\subsection{A long-range equatorial origin?}

Having excluded the possibility of a short-range troposphere-stratosphere transport, we now consider the hypothesis of long-range horizontal transport. In order to check for the origin of the aerosol increase, associated with a low-PV decrease, the high resolution advection MIMOSA model (Hauchecorne et al., 2001) has been used to produce a continuous evolution of PV fields for the period from April 21 to 30. The MIMOSA model is an enhancement of the original contour advection algorithm of Norton (1994) and Waugh and Plumb (1994). In the lower stratosphere $\mathrm{PV}$ is assumed to be conserved on isentropic surfaces for 

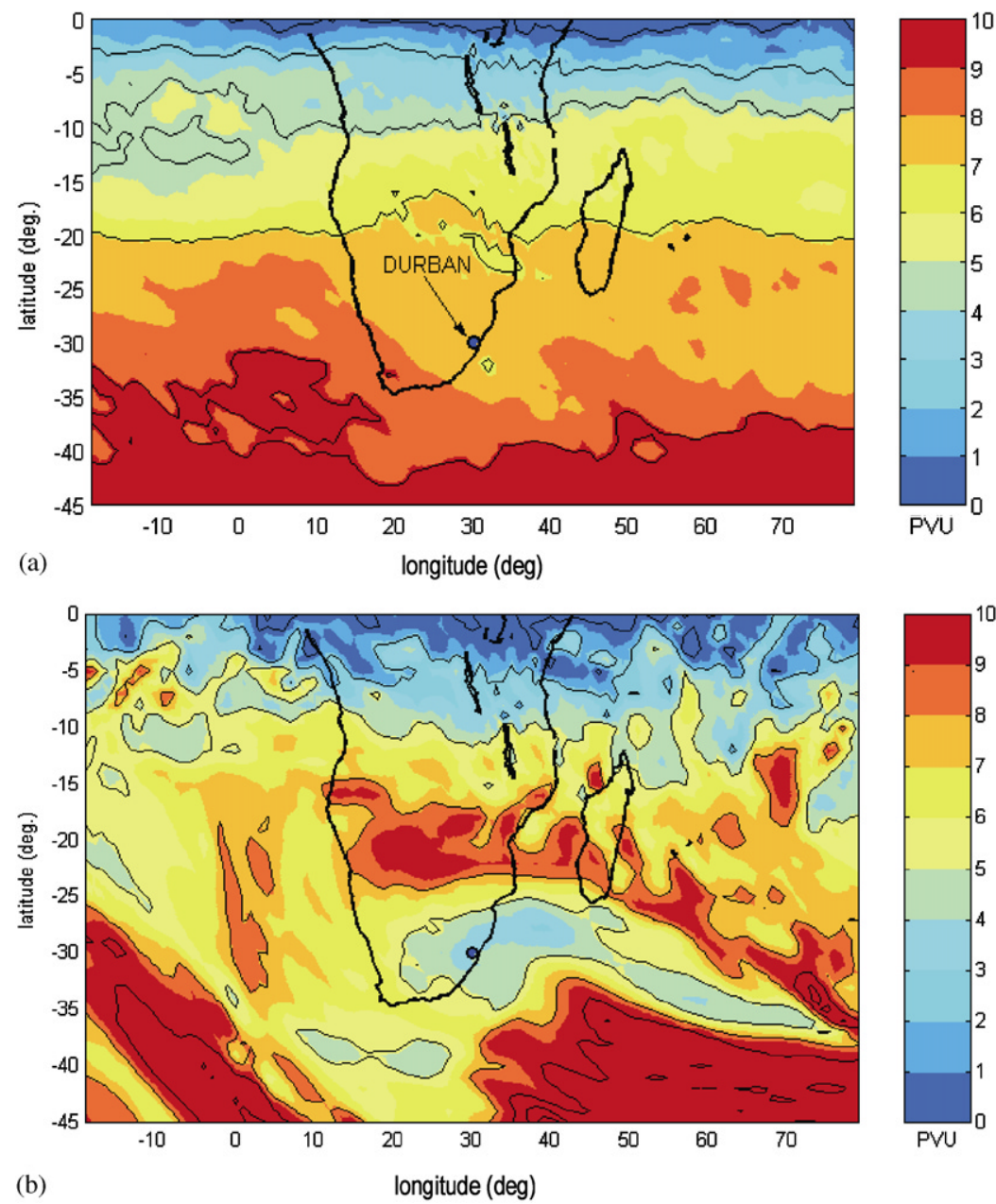

(b)

Fig. 3. Potential vorticity analyses derived from ECMWF fields, for the $400 \mathrm{~K}$ potential temperature level. (a) PV mean fields from April 18 to May 10, 1999, and (b) PV field on April 29, 1999.

periods of 1 week (Orsolini, 1995). For periods longer than 1 week, the diabatic transport across isentropic surfaces due to radiative cooling and warming of air as well as the diabatic advection term in the PV equation have to be taken into account. See Haynes and McIntyre (1990) for further discussion on PV conservation. The information on diabatic changes in the PV field, at least for larger scales, can be extracted from ECMWF fields. This is made by applying to the MIMOSA PV field a relaxation toward the ECMWF PV field with a time constant of 10 days. In order to preserve the filamentation structure, the relaxation term is only applied to scales larger than $300 \mathrm{~km}$. To do that, both MIMOSA and ECMWF fields are smoothed to the same resolution and the difference between the two fields is used to compute the relaxation term.

MIMOSA has been used for real time 5 day forecasts of the PV fields and has been found useful for the detection of sub-tropical and polar filaments and alert release in the frame of the METRO project (MEridional TRansport of Ozone in the lower stratosphere, a research project included in the European campaign THESEO (Heese et al., 2001)).

Four advected-PV maps, derived for the $400 \mathrm{~K}$ level from the MIMOSA model are presented in Fig. 5. A low-PV air mass of tropical origin (over the South American continent) stretches latitudinally in the form of a "tongue" towards the southern mid-latitudes. The tropical air mass was localised close to Brazil on April 23 (see Fig. 5a), and moved south-eastwards in the days thereafter. On April 25, the forward edge of the event is positioned in the middle of the Atlantic Ocean around $30^{\circ} \mathrm{S}$ and has a south-easterly movement (see Fig. 5b). On April 28, the forward edge is situated near the west coast of southern Africa, extending towards the north (Fig. 5c). The tropical low-PV filament has elongated and covers nearly all of South Africa by April 29 and 30 (Fig. 5d). 


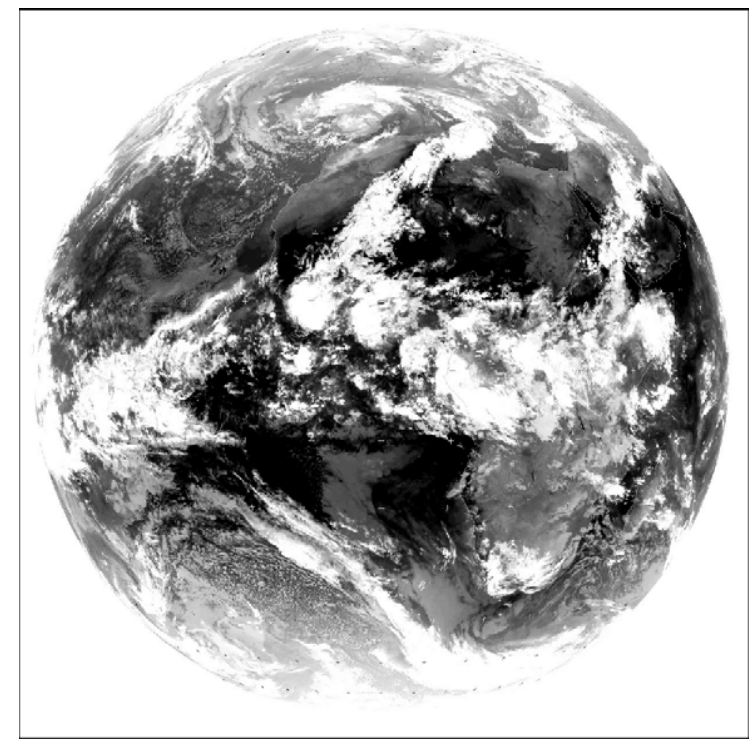

Fig. 4. Water vapour and cloud distributions in the troposphere derived from MeteoSat satellite for April 29, 1999.
Moreover, kinematic back-trajectories calculated from ECMWF (not shown) are in a close agreement with the advection contour model, and show the same origin for the stratospheric air mass over Durban.

\section{Conclusion}

The central line of this work is the use of both LIDAR measurements and modelling in order to analyse an isentropic transport event through the southern subtropical barrier. We first focused on the use of aerosol profiles obtained by LIDAR over Durban, South Africa. Because of their life expectancy, stratospheric aerosols provide a good tracer. Aerosols can thus be used to study stratospheric dynamics and notably to study transport from the tropical stratospheric reservoir to mid-latitudes. As reported by several authors (Trepte and Hitchman, 1992; McCormick and Viega, 1992), the tropical stratospheric reservoir has an air mass that is distinctly different from that in the mid-latitude stratosphere.

That is evidenced in Fig. 6, which shows a tropical and a subtropical height vs. time cross-section of aerosol
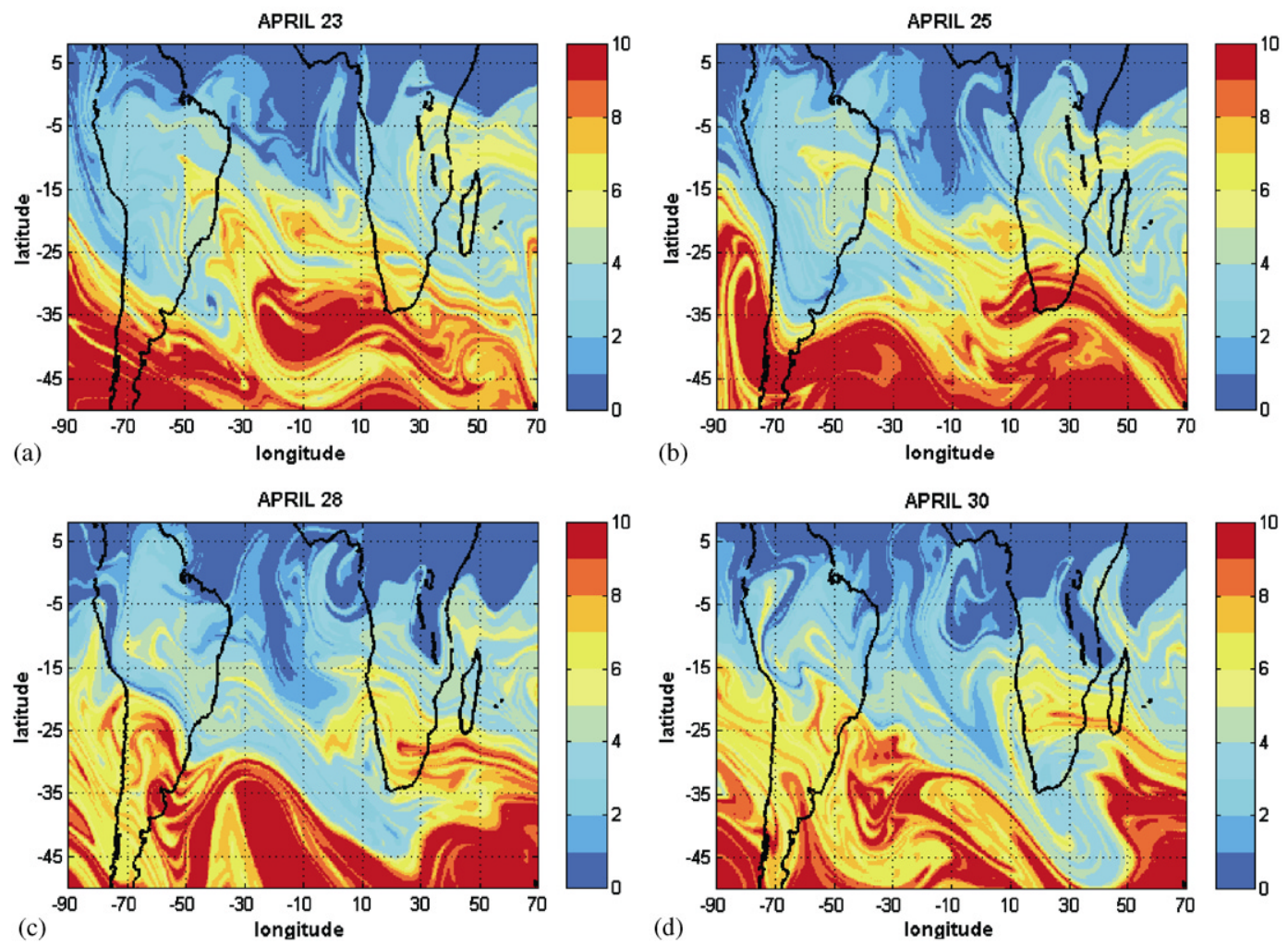

Fig. 5. Advected-PV contours as obtained with the MIMOSA model for April (a) 23, (b) 25, (c) 28 and (d) 30, 1999. The four PV contours are for the $400 \mathrm{~K}$ potential temperature level. 

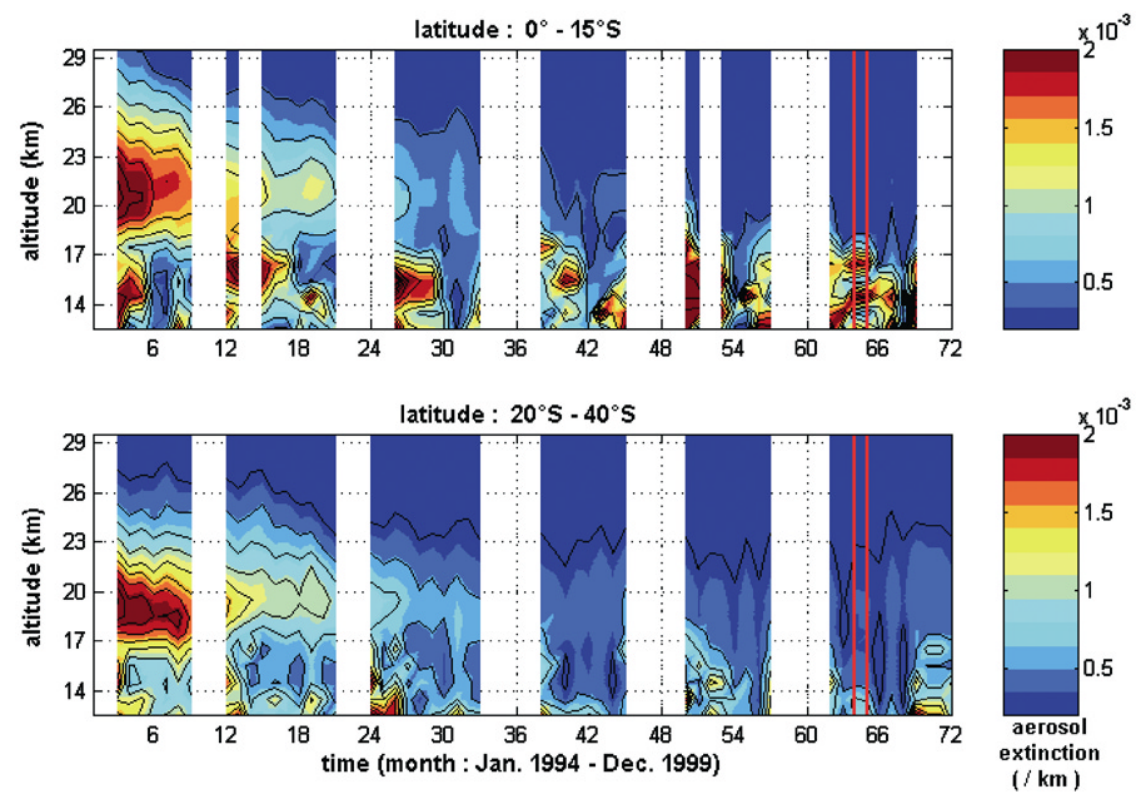

Fig. 6. Time vs. height cross-sections of aerosol extinction derived from SAGE-2 profiles obtained from the 525-nm wavelength channel, for the period from January 1994 to December 1999 . The upper and lower plates present the $0-15^{\circ} \mathrm{S}$ and $20-40^{\circ} \mathrm{S}$ latitudinal bands, respectively. The heavy red solid lines frame the period from April to June 1999.

extinction as recorded by the $525-\mathrm{nm}$ wavelength channel of the SAGE-2 experiment, from 1994 to 1999. Whatever the period of observation is, one can observe that aerosol distributions in the lower stratosphere are different in the tropical zone and the subtropics. During the period from April to June 1999 (indicated with two vertical heavy lines), a $2 \mathrm{~km}$-layer with a maximum extinction value of $\approx 1.7 \mathrm{~km}^{-1}$ was evident in the tropical lower stratosphere; while in the subtropical stratosphere the maximum extinction value only reached $\approx 0.6 \mathrm{~km}^{-1}$. This indicates that the observed aerosol loading event over Durban can correspond to a transport process of air mass from tropics.

Examination of MIMOSA output PV-maps at 380 and $420 \mathrm{~K}$ potential temperature levels (not shown) show almost the same filamentary development, as for the $400 \mathrm{~K}$ level (see Fig. 5), with the same trajectory and during the same period. The detected horizontal transport event in the lower stratosphere concerns several isentropic levels in the lower stratosphere, in agreement with LIDAR observations over the Durban site (see Fig. 2).

All these results, LIDAR observation together with SAGE-2 measurements, the PV-maps, and the MIMOSA model retrieval of filamentary structures derived from ECMWF fields, agree with each other supporting the hypotheses of a horizontal transport in the lower stratosphere of air mass from tropics towards the subtropics and mid-latitudes.

Moreover, it is well known that the winter stratosphere is disrupted by wave activity, chiefly gravity and planetary waves. These waves are mainly generated in the troposphere and propagate with the westerly winds in winter through the middle atmosphere. It is also known that horizontal air mass exchanges between the tropical stratospheric reservoir and mid-latitudes are episodic and take place through the subtropical barrier due to planetary wave breaking. Indeed, it is the large-scale Rossby waves in the westerlies that pull air masses and tracers from the tropics into mid-latitudes in the form of large-scale filaments through the surf zone (Leovy et al., 1985; McIntyre and Palmer, 1984).

Using the same LIDAR data base recorded over Durban during the same period as in the present study, Bencherif et al. (2000) have shown that the daily variability of the local thermal structure was getting large, as the zonal wind component was becoming westerly and Rossby waves could propagate upward. Furthermore, in recent years and mostly in the northern hemisphere, there has been much interest in understanding the effects of mixing barriers on either side of the tropical stratosphere. With regard to the latitudinal extent of the air mass transport, coupling of observations and modelling is therefore essential in studying large-scale events.

In order to understand and quantify the meridional exchange events through the southern subtropical barrier, we carry on monitoring the LIDAR over Durban, in parallel with similar observations over Reunion Island $\left(20.8^{\circ} \mathrm{S}, 55.5^{\circ} \mathrm{E}\right)$.

\section{Acknowledgements}

The authors wish to acknowledge the South African Weather Service and ECMWF for providing meteorological 
data and the G.R.T.R. (University of Strasbourg, France) for providing the Meteosat data. We also want to thank the French Embassy at Pretoria, the National Research Foundation (South African agency), le Ministère de l'Education Nationale de l'Enseignement Supérieur et de la Recherche, le Ministère des Affaires Etrangères et de la Coopération and le Conseil Général de la Réunion, for their financial support.

\section{References}

Baray, J.L., Daniel, V., Ancellet, G., Legras, B., 2000. Planetary scale tropopause folds in the southern subtropics. Geophysical Research Letters 27, 353-356.

Bencherif, H., Morel, B., Moorgawa, A., Michaelis, M.M., Leveau, J., Porteneuve, J., Hauchecorne, A., Faduilhe, D., 2000. Observation and first validation of stratospheric temperature profiles obtained by a Rayleigh-Mie LIDAR over Durban, South Africa. South African Journal of Science 96, 487-492.

Brasseur, G., Granier, C., 1992. Mount Pinatubo aerosols, chlorofluorocarbons and ozone depletion. Science 257, 12391242.

Chazette, P., David, C., Lefrère, J., Godin, S., Pelon, J., Mégie, G., 1995. Comparative LIDAR study of optical, geometrical, and dynamical propreties of stratospheric post-volcanic aerosols, following the eruptions of El-Chichon and Mount Pinatubo. Journal of Geophysical Research 100, 23,195-23,207.

Chen, P., Holton, J.R., O’Neill, A., Swinbank, R., 1994. Isentropic mass exchange between the tropics and extratropics in the stratosphere. Journal of Atmospheric Science 51, 3006-3018.

Chu, W.P., McCormick, M.P., Lenoble, J., Brogniez, C., Pruvot, P., 1989. SAGE II inversion algorithm. Journal of Geophysical Research 94, 8339-8351.

David, C., Bekki, S., Godin, S., Mégie, G., Chipperfield, M.P., 1998. Polar stratospheric clouds climatology over Dumont d'Urville Between 1989 and 1993 and the influence of volcanic aerosols on their formation. Journal of Geophysical Research $103,22,163-22,180$.

Grant, W.B., Browell, E.V., Long, C.S., Stowe, L.L., Graiger, R.G., Lambert, A., 1996. Use of volcanic aerosols to study the tropical reservoir. Journal of Geophysical Research 101, 3973-3988.

Hauchecorne, A., Chanin, M.L., 1980. Density and temperature profiles obtained by LIDAR between 35 and $70 \mathrm{~km}$. Geophysical Research Letters 7, 565-568.

Hauchecorne, A., Godin, S., Marchand, M., Heese, B., Souprayen, C., 2001. Quantification of the transport of chemical constituents from the polar vortex to middle latitudes in the lower stratosphere using the high-resolution advection model MIMOSA and effective diffusivity. Journal of Geophysical Research, in press.

Haynes, P.H., McIntyre, M.E., 1990. On the conservation and impermeability theorems for potential vorticity. Journal of Atmospheric Science 47, 2021-2031.

Haynes, P., Shuckburgh, E., 2000. Effective diffusivity as a diagnostic of atmospheric transport. Journal of Geophysical Research 105, 22,777-22,794.
Heese, B., Godin, S., Hauchecorne, A., 2001. Forcast and simulation of stratospheric ozone filaments: a validation of a high-resolution potential vorticity advection model by airborne ozone lidar measurements in winter 1998-1999. Journal of Geophysical Research 106, 20,011-20,024.

Holton, J.R., Haynes, P.H., McIntyre, M.E., Douglass, A.R., Rood, R.B., Pfister, L., 1995. Stratosphere-troposphere exchange. Reviews of Geophysics 33, 403-439.

Horinouchi, T., Sassi, F., Boville, B.A., 2000. Synoptic-scale Rossby waves and the geographic distribution of lateral transport routes between the tropics and extratropics in the lower stratosphere. Journal of Geophysical Research 105, 26,57926,592.

Keckhut, P., Hauchecorne, A., Chanin, M.L., 1993. A critical review of the database acquired for the long-term surveillance of the middle atmosphere by the french Rayleigh LIDARs. Journal of Atmospheric Oceanic Technology 10, 850-867.

Kinninson, D.E., Grant, K.E., Connell, P.S., Rotman, D.A., Wuebbles, D.J., 1994. The chemical and radiative effects of the Mount Pinatubo eruption. Journal of Geophysical Research 99, $25,705-25,731$.

Klett, J.D., 1981. Stable analytical inversion solution for processing LIDAR returns. Applied Optics 20, 211-220.

Klett, J.D., 1985. LIDAR inversion with variable backscatter/ extinction ratios. Applied Optics 24, 1638-1643.

Labitzki, K., McCormick, M.P., 1992. Stratospheric temperature increases due to Pinatubo aerosols. Geophysical Research Letters 19, 207-210.

Leovy, C.B., Sun, C.-R., Hitchman, M.H., Remsberg, E.E., Russel, J.M., Gordley, L.L., Gille, J.C., Lyjak, L.V., 1985. Transport of ozone in the middle stratosphere: evidence for planetary wave breaking. Journal of Atmospheric Science 42, 230-244.

McCormick, M.P., 1987. SAGE II: an overview. Advances in Space Research 7, 219-226.

McCormick, M.P., Viega, R.E., 1992. SAGE II measurements of early Pinatubo aerosols. Geophysical Research Letters 19, $155-158$

McIntyre, M.E., Palmer, T.N., 1984. The "surf zone" in the stratosphere. Journal of Atmospheric and Terresterial Physics 46 (9), 825-849.

Norton, W.A., 1994. Breaking Rossby waves in a model stratosphere diagnosed by vortex-following coordinate system and a contour advection technique. Journal of Atmospheric Science 51, 654-673.

Orsolini, Y.J., 1995. On the formation ozone laminae at the edge of the Arctic polar vortex. Quarterly Journal of the Roy Meteorological Society 121, 1923-1941.

Randel, W.J., Gille, J.C., Lahoz, A.E., 1993. Stratospheric transport from tropics to middle latitudes by planetary wave mixing. Nature 365, 533-535.

Robock, A., Mao, J., 1992. Winter warming from large volcanic eruption. Geophysical Research Letters 19, 2405-2408.

Roumeau, S., Brémaud, P., Rivière, E., Baldy, S., Baray, J.L., 2000. Tropical cirrus clouds: a possible sink for ozone. Geophysical Research Letters 27, 2233-2236.

Shapiro, M.A., Kennedy, P.J., 1981. Research aircraft measurements of jet stream geostrophic and ageostrophic winds. Journal of Atmospheric Science 38, 2642-2652.

Solomon, S., Portmann, R.W., Garcia, R.R., Thomson, L.W., Poole, L.R., McCormick, M.P., 1996. The role of aerosol variations in 
antropogenic ozone depletion in northern mid-latitudes. Journal of Geophysical Research 101, 6713-6727.

Steinbrecht, W., Jager, H., Adriani, A., di Donfrancesco, G., Barnes, J., Beyerle, G., Neuber, R., David, C., Godin, S., Donovan, D., Carswell, A.I., Gross, M., McGee, T., Masci, F., D'Altorio, A., Rizi, V., Visconti, G., McDermid, I.S., Megie, G., Mielke, A., Stein, B., Wedekind, C., Nagai, T., Uchino, O., Nakane, H., Osborn, M., Winker, D., 1996. NDSC intercomparison of stratospheric aerosol processing algorithms. Advances in Atmospheric Remote Sensing with LIDAR 501-504.

Thomason, L.W., Poole, L.R., Deshler, T., 1997. A global climatology of stratospheric aerosol surface area density deduced from Stratospheric Aerosol and Gas Experiment II measurements: 1984-1994. Journal of Geophysical Research $102,8967-8976$.
Trepte, C.R., Hitchman, M.H., 1992. Tropical stratospheric circulation deduced from satellite aerosol data. Nature 355, $626-628$

Wang, P.H., McCormick, M.P., Swissler, T.J., Osborn, M.T., Fuller, W.H., Yue, G.K., 1989. Interference of stratospheric aerosol composition and size distribution from SAGE II satellite measurement. Journal of Geophysical Research 94, 8435-8446.

Waugh, D.W., 1993. Subtropical stratospheric mixing linked to disturbance of the polar vortices. Nature $365,535-537$.

Waugh, D.W., 1996. Seasonal variation of isentropic transport out of the tropical stratosphere. Journal of Geophysical Research 101 (D2), 4007-4023.

Waugh, D.W., Plumb, R.A., 1994. Contour advection with surgery: a technique for investigating fine-scale structure in tracer transfer. Journal of Atmospheric Science 51, 530-540. 